\title{
Gestão estratégica de pessoas na administração indireta do setor público federal: na prática, ainda um discurso
}

Ana Lúcia Neves de Moura

Fundação Joaquim Nabuco (Fundaj)

Bruno Campello de Souza

Universidade Federal de Pernambuco (UFPE)

O artigo tem como objetivo analisar o discurso e a prática da área de gestão de pessoas na administração indireta do setor público federal brasileiro, sob a perspectiva da Teoria Institucional. Trata-se de pesquisa quantitativa, com a aplicação de questionário a 43 órgãos públicos. Constatou-se a discrepância entre o discurso e a prática. A inserção estratégica da gestão de pessoas nas estruturas e processos decisórios das instituições públicas ainda é uma questão a ser conquistada. Os resultados sugerem que restrições relacionadas à qualificação dos profissionais de recursos humanos, à ausência de uma gestão estratégica e ao legado histórico-cultural das instituições têm limitado a capacidade de resposta da gestão de pessoas às novas demandas de $\mathrm{RH}$, dificultando as inovações e mudanças nessa área.

Palavras-chave: administração estratégica, gestão de pessoas, administração pública indireta

[Artigo recebido em 28 de maio de 2015. Aprovado em 3 de maio de 2016.] 
Gestión estratégica de personas en la administración indirecta del sector público federal: en la práctica, todavía un discurso

El artículo tiene como objetivo analizar el discurso y la práctica del área de gestión de personas en la administración indirecta del sector público federal brasileño desde la perspectiva de la Teoría Institucional. Se trata de una investigación cualitativa, con la aplicación de cuestionario a 43 órganos públicos. Se constató la discrepancia entre el discurso y la práctica. La inserción estratégica de la gestión de personas en las estructuras y procesos decisorios de las instituciones públicas es aún una cuestión a ser conquistada. Los resultados sugieren que restricciones relacionadas a la cualificación de los profesionales de recursos humanos, a la ausencia de una gestión estratégica y al legado histórico-cultural de las instituciones han limitado la capacidad de respuesta de la gestión de personas a las nuevas demandas de $\mathrm{RH}$, dificultando las innovaciones y los cambios en esa área.

Palabras clave: administración estratégica, gestión de personas, administración pública indirecta

Strategic human resource management in the indirect federal public administration: in practice, still a speech

The article aims to analyze the discourse and practice of human resource management area in Brazilian indirect federal public administration, from the perspective of institutional theory. This is a quantitative research with the application of questionnaire to 43 public agencies. A discrepancy between theory and practice was found. The strategic role of human resource management in decision-making structures and processes of public institutions is still a question to be won. The results suggest that restrictions relating to human resources professional's qualification, the lack of a strategic management and institutions historicalcultural legacy have limited the responsiveness of human resource management to the new demands of $\mathrm{HR}$, hampering innovation and change in this area.

Keywords: strategic administration, people management, indirect public administration 


\section{Introdução}

O desenvolvimento tecnológico crescente, a competição global e a diversidade da força de trabalho aliados à busca constante por novas formas de organização e gerenciamento do trabalho têm colocado os indivíduos e as organizações diante de experiências simultâneas e contraditórias, contribuindo para revelar e intensificar os paradoxos organizacionais. Tensões como velho/novo, controle/flexibilidade, indivíduo/grupo, qualidade/custo, estabilidade/mudança, global/local, discurso/ prática, autonomia/conformidade, passado/futuro, liberdade/vigilância estão cada vez mais presentes na vida organizacional e são exemplos de paradoxos organizacionais (LEANA; BARRY, 2000; LEWIS, 2000; VASCONCELOS; VASCONCELOS, 2004).

Mudança e pluralismo (de ideias, entre pessoas, dentro das organizações e entre essas) são estimulados por essas tensões paradoxais, de modo que concepções de mudança como suave, linear e planejada desaparecem. O paradoxo emerge, portanto, quando existe uma tensão entre duas realidades opostas, como dois lados de uma mesma moeda. Paradoxos podem indicar uma variedade de elementos contraditórios (perspectivas, sentimentos, mensagens, demandas, identidades, interesses ou práticas); são socialmente construídos, a partir da tendência dos indivíduos de simplificar a realidade (cada vez mais complexa, ambígua e em constante mudança) por meio de percepções polarizadas; e só se tornam aparentes por meio da reflexão ou interação social (EISENHARDT, 2000; LEWIS, 2000).

Concomitante com a existência de ambiguidades, frequentemente encontra-se uma alta incidência de sintomas de stress, sentimento de frustração, ansiedade, resistência e emergência de conflitos que interferem nos processos de mudança organizacional. Contudo, a gestão dessa dualidade é uma oportunidade de explorar e revelar as ambiguidades e contradições que contribuem para essas tensões, de forma que o paradoxo é uma "faca de dois gumes", considerando que as tensões decorrentes tanto podem atuar como um gatilho para a mudança, como podem, simultaneamente, impedi-la. Assim, ao invés de ignorar os paradoxos presentes na vida organizacional, ou simplesmente classificá-los como perniciosos à organização, é imprescindível que sejam identificados, discutidos e gerenciados, a fim de canalizar sua energia para as transformações pretendidas (EISENHARDT, 2000; LEWIS, 2000).

Entre os paradoxos organizacionais, o paradoxo discurso versus prática tem sido um dos mais citados nos estudos organizacionais. Vasconcelos e Vasconcelos (2004) consideram que em decorrência do cenário de mudança e competitividade que se instalou nas últimas décadas, as organizações adotam novos discursos informacionais, contudo as mudanças nos sistemas produtivos demoram a ocorrer, em função da complexidade envolvida nesses processos. Assim, o paradoxo 
discurso-prática envolve discursos que geram expectativas, mas que não se realizam, contribuindo para o surgimento de reações defensivas, angústia, frustrações e stress nas organizações (LACOMBE; TONELLI, 2004). Aprender a gerenciar essas tensões é imprescindível para se alcançar as transformações que se quer implementar nos processos de mudança conduzidos nas organizações (LEWIS, 2000).

O objetivo deste artigo é analisar o discurso e a prática de gestão de pessoas em órgãos da administração indireta no setor público federal, à luz da Teoria Institucional. A discussão sobre o papel estratégico da área de RH e sua importância para o futuro das organizações - privadas e públicas - se desenvolve há décadas (GUeSt, 2011; LEgGe, 2005; PAAUWE, 2004; SCHIKMANN, 2010). Os títulos dos livros especializados e a quantidade de estudos e de serviços de consultoria nessa área, além do discurso presente nas organizações, refletem a tendência de valorização da gestão de pessoas nas organizações (PAAUWE, 2004). Contudo, evidências empíricas revelam que essa área enfrenta dificuldades em fazer a transição de área operacional para área estratégica, seja no setor privado, seja no setor público, como será apresentado na seção seguinte.

Outro aspecto que vale a pena destacar é que as contradições entre o discurso e a prática nas organizações têm despertado o interesse da academia, não apenas na área de RH (ver estudos em outras áreas: AgUIAR; MELLO JúNIOR, 2006; ÄHLSTRÖM, 2010; Amaral Filho; Machado-Da-Silva, 2006; Guerreiro; Frezatti; CaSado, 2006). Esse fenômeno tem sido colocado como um paradoxo organizacional (BOSELIE; Brewster; PAaUWe, 2009; LeWIS, 2000; VAsconcelos; VASCONCElos, 2004) com implicações, inclusive, para a saúde e satisfação das pessoas no trabalho (LACOMBE; TONELLI, 2004; SILVA; VERGARA, 2003).

Boselie, Brewster e Paauwe (2009) esclarecem que, se as questões sobre dualidades, paradoxos e ambiguidades têm dominado a literatura sobre gestão de recursos humanos nos últimos trinta anos e, embora cada vez mais se venha descobrindo evidências sobre essas questões, esse é um debate que ainda está em curso.

É importante ressaltar, ainda, que o paradoxo discurso-prática na área de gestão de recursos humanos tem sido apontado como fator significativo para o baixo comprometimento (DEMo et al., 2011), desmotivação e insatisfação dos funcionários, impactando negativamente o desempenho organizacional (KHILI; WANG, 2006), contribuindo para uma maior resistência à mudança e interferindo na qualidade da relação entre gestores e funcionários (GILL; MEYER, 2011), o que ratifica a relevância desta pesquisa. 


\section{A contradição entre o discurso e a prática na gestão de pessoas}

O termo gestão estratégica de recursos humanos surgiu no final da década de 1980, primeiro entre os acadêmicos e gerentes, para então se disseminar nos anúncios de emprego, nos cursos e na literatura especializada. A preocupação com o gerenciamento das pessoas nas organizações, com o objetivo de alcançar a vantagem competitiva, tomou uma dimensão tal que na década de 1990 virou um verdadeiro "mantra" entre os gestores, tornando-se popular, também, entre os acadêmicos, e contribuindo para uma profusão de livros populares sobre o tema (PAAUWE, 2004).

O conceito contemporâneo de gestão estratégica de recursos humanos entende que as políticas e práticas relativas ao gerenciamento das pessoas na organização devem estar inter-relacionadas e integradas à estratégia organizacional e sejam resultado de uma postura mais proativa que reativa (BOON et al.; 2007; KEPES; DELERY, 2007);_estejam voltadas para a criação de uma ambiência que favoreça o desenvolvimento de competências (CARBOne et al., 2005; LE BOTERF, 2006; ZARIFIAN, 2003) e da sustentabilidade organizacional (FrEITAS; JABBOUR; SANTOS, 2009; LIEBOWITZ, 2010; RIMANOCZY; PEARSON, 2010); e considerem as expectativas e necessidades das pessoas (BURKE; COOPER, 2006; DUTRA, 2008).

A constatação da importância da gestão de pessoas também vem ganhando espaço nos debates que envolvem a melhoria e a eficácia dos serviços públicos (Amaral, 2006; CARvalho et al., 2009; OCDE, 2010; SChikMAnN, 2010). O setor público tem estado sob pressão nas últimas décadas, tanto em relação à prestação pública de contas e ao controle dos gastos, como em relação à qualidade e adequação dos serviços que oferece aos cidadãos. A introdução dos princípios do modelo gerencial no setor público acentuou tais pressões (LEGGE, 2005) e trouxe repercussões importantes para a gestão de pessoas, chamando a atenção para o seu papel estratégico nas organizações públicas e para a necessidade de modernização da estrutura de pessoal (SCHIKMANN, 2010).

Contudo, no Brasil a prática de ações estratégicas deu-se com anos de atraso, embora a necessidade de tratar a área de $\mathrm{RH}$ como estratégica já estivesse presente na literatura. Historicamente, em especial no Brasil, a área de RH tem se envolvido mais com atribuições normativas, com pouca densidade estratégica (BARBOSA, 2005).

Pesquisas mostram que, embora os gerentes de RH concordem com a posição estratégica do seu setor na empresa, esses não conseguem definir o que consideram uma ação estratégica, chegando a confundir ações operacionais como se fossem estratégicas (CÉSAR; BIDO; SAAD, 2007; MOURA; SOUZA, 2014). Não obstante esses gerentes afirmem que atuam de forma estratégica, essa realidade não é plenamente 
observável (FIGUEIREDo et al., 2008). Há ambivalências entre discurso e prática na área de gestão de pessoas. Apesar da sofisticação dos modelos de relações de trabalho e de gestão, no cotidiano organizacional o que se observa é a adaptação ou o desenvolvimento de metodologias próprias (DIAS; LOPES; DALLA, 2007).

A tendência das organizações brasileiras de adotarem modismos e de importarem modelos de gestão estrangeiros pode estar contribuindo, em parte, para a incoerência apresentada pela área. A importação de modelos sofisticados e de ferramentas de gestão de última geração confere ares de modernidade à área de $\mathrm{RH}$, contudo o que se observa é uma desarticulação entre esses modelos e o não alinhamento desses à estratégia da organização (TANURE; EVANS; CANÇADO, 2010).

O discurso sobre a importância dos recursos humanos adotado pelas diretorias e profissionais de $\mathrm{RH}$ muitas vezes não encontra respaldo no cotidiano da gestão (TANURE; EvANS; CANÇADo, 2010). Outras vezes, a cúpula diretiva da organização assume a definição do modelo de gestão de pessoas, com pouca ou nenhuma presença da área competente. Esta só é envolvida no momento de operacionalização do modelo, assumindo uma posição de coadjuvante (BARBOSA; FERRAZ; LOPES, 2002).

Tal constatação também é observada em outros países. Há pouca evidência de que a gestão estratégica de $\mathrm{RH}$ venha sendo aplicada na mesma escala com que se apresenta na retórica dos acadêmicos, gerentes de linha, gestores de RH e consultores (LEGGE, 2005). Ao analisar a realidade americana, Kochan (2007) chama a atenção para o fato de que essa dificuldade em concretizar o tão anunciado potencial de maior status, influência e resultados tem refletido numa crise de confiança e perda de legitimidade para o profissional de RH. Ramlall (2006) identificou que parte significativa do tempo do profissional de $\mathrm{RH}$ americano ainda está voltada para atividades transacionais (ao invés de transformacionais), e constatou a necessidade desse profissional desenvolver as competências que de fato assegurem a sua contribuição para o sucesso da organização.

Estudos ingleses mostram ainda que, embora exemplos de implementação de gestão estratégica de pessoas realmente existam, o quadro geral retrata que a implementação de técnicas associadas a esse modelo tem sido provisória, oportunista e fragmentada (LEGGE, 2005). Ashton, Haffenden e Lambert (2004) constataram que as unidades inglesas de RH têm baixa reputação e uma atuação com ênfase nos processos internos da área, com pouca ligação com os objetivos organizacionais.

Mesmo que grande parte dos dirigentes e dos gestores de $\mathrm{RH}$ reconheça a contribuição decisiva das pessoas para o desempenho organizacional e a importância do desenvolvimento das competências, Le Boterf (2003), estudioso francês, admite 
que desses somente uma minoria harmoniza sua política com o discurso sobre a prioridade da valorização e desenvolvimento das pessoas.

$\mathrm{Na}$ Espanha, embora as empresas venham adotando práticas globais de $\mathrm{RH}$, Cabrera e Carretero (2005) concluem que a área ainda é percebida como uma função de baixo status, com pouca orientação estratégia, recursos escassos e ação reativa.

Ao estudarem empresas do Brasil e do Peru, Coda et al. (2009) constatam que em ambos os países a capacidade da área de $\mathrm{RH}$ de dar suporte à estratégia organizacional não corresponde à importância estratégica atribuída ao setor e observam que a área está mais preocupada com processos internos e desempenha atividades operacionais.

Em organizações neozelandesas, Rasmussen, Andersen e Haworth (2010) concluem que há pouca evidência de que o $\mathrm{RH}$ e seus profissionais desempenhem um papel significativo nas tomadas de decisões estratégicas. Quando se trata de fazer parte da equipe de gerenciamento sênior e participar das decisões estratégicas, o status da área parece estar aquém, com poucos avanços na última década.

Estudos na Austrália mostram, ainda, que o gap entre o discurso e a realidade da gestão de pessoas impacta as organizações, apresentando resultados negativos em termos de comprometimento, produtividade e satisfação dos funcionários, promovendo a resistência à mudança e contribuindo para um relacionamento insatisfatório entre gestores e funcionários (GILL; MEYER, 2011).

No setor público brasileiro, essa questão não se apresenta de forma diferente. De fato, a gestão pública de recursos humanos tem sido marcada por uma série de descontinuidades e dificuldades na estruturação dos seus sistemas, muitas vezes sequer sendo tema da agenda de governo (CARVALHo et al., 2009; PIRES et al., 2005). A sucessão de reformas desconexas ou que não tiveram continuidade também contribuiu para criar um clima de confusão, desconfiança, cinismos e resistência à mudança nessa área (OCDE, 2010).

Na fase mais recente da administração pública federal brasileira, destaca-se a introdução da gestão por competências como modelo orientador da gestão de pessoas (BRASIL, 2006). Entre os fatores que têm contribuído para impulsionar a aplicação desse modelo de gestão no serviço público em vários países, a OCDE (2010) aponta o interesse dos governos em: investir nas habilidades gerenciais de servidores públicos de alto escalão; introduzir formas flexíveis de trabalho no setor público; e aprimorar o planejamento estratégico da força de trabalho (indo além das variáveis quantidade e custo) e o desempenho no serviço público.

Vale esclarecer que a gestão por competência não se contrapõe ao modelo de gestão estratégica de $\mathrm{RH}$, mas o complementa. Dessa forma, orientando-se pelos objetivos estratégicos estabelecidos, as políticas e ações de RH voltam-se para 
a identificação das competências humanas necessárias à concretização desses objetivos e para o desenvolvimento dessas competências. Nesse modelo, portanto, os parâmetros e os instrumentos de gestão de pessoas estão direcionados para o propósito estratégico da organização, afirma Dutra (2008).

O conceito de gestão por competência foi incorporado à administração pública federal brasileira em 2006, com a promulgação do Decreto no 5.707/2006, que instituiu a Política e as Diretrizes para o Desenvolvimento de Pessoal, tornandose, como reconhecem Carvalho et al. (2009), o referencial para a gestão de pessoas do setor público federal. Contudo, estudos recentes constatam que, apesar dos avanços, a gestão pública de RH ainda está longe de contribuir de forma efetiva para a adequação do perfil dos servidores públicos às demandas plurais e complexas da sociedade contemporânea, que exigem do setor público ações eficazes e resultados de qualidade.

Além disso, a implementação desses novos modelos implica na ruptura com determinados padrões gerenciais em vigor e no profundo repensar de outros aspectos decorrentes da formação histórica da administração pública e de traços culturais próprios desse setor (SCHIKMANN, 2010).

No diagnóstico que realiza sobre a gestão de pessoas no Governo Federal, no período de 1995 a 2009, Marconi (2010) encontra distorções que impedem uma política de $\mathrm{RH}$ mais efetiva, que de fato possa contribuir para o alcance do perfil desejado para a força de trabalho desse setor. Destacam-se a ausência de um planejamento da força de trabalho que dimensione o contingente e o perfil necessários e a ausência de uma estrutura de incentivos que estimule o desenvolvimento profissional.

Em relatório no qual avalia a gestão de $\mathrm{RH}$ do Governo Federal brasileiro, a OCDE (2010) deixa claro que o planejamento estratégico da força de trabalho decorre ainda de situações emergenciais, pedidos corporativistas e demandas dos órgãos, em vez de ser fruto de uma visão estratégica que considere as competências críticas ao cumprimento da missão e das metas organizacionais (atuais e futuras) e de reflexões sobre as alterações das prioridades do governo, mudanças nas organizações etc.

Embora o reconhecimento da importância da gestão de $\mathrm{RH}$ para o setor público esteja presente no discurso do Governo Federal brasileiro, quando esse introduz o conceito de gestão por competências, destaca que a modernização da gestão de pessoas deve estar no cerne de uma proposta séria de reformulação da máquina estatal e associa a efetividade das políticas públicas à qualidade da força de trabalho (BRASIL, 2009). Estudos mostram que as instituições públicas federais têm tido dificuldade no processo de implementação do modelo de gestão por competências. 
Pesquisa feita nos ministérios e na Casa Civil da Presidência da República constatou, entre outros, que a implementação do modelo estava fundamentada mais no discurso que na definição de metas sistemáticas e que a área de RH desses órgãos apresentava pouca legitimação política para implementar o modelo (BRASIL, 2009).

Em estudo semelhante, ao analisar as agências de regulação do Governo Federal, Fonseca e Meneses (2011) identificaram que nenhum desses órgãos possui a gestão por competências consolidada. Apenas duas agências adotaram o modelo, contudo a implantação se restringiu aos processos de capacitação e de avaliação, não envolvendo integralmente o sistema de $\mathrm{RH}$, como orienta a literatura sobre o tema (CARBone et al., 2005; Dutra, 2008).

Pesquisa realizada com uma empresa pública do setor bancário revela que embora essa organização estivesse em processo avançado de implantação da gestão por competências, as práticas vigentes de gestão de pessoas não forneciam a base necessária à adoção e sustentação desse modelo (CASTRO; KILIMNIK; SANT'ANNA, 2008).

Estudos no âmbito público mostram que as atividades operacionais ainda ocupam grande parte do tempo dos gestores de RH (NASCIMENTO; SIMÕES, 2011) e que os servidores apresentam dificuldade em perceber as iniciativas dessa área e reconhecer sua importância para a melhoria da gestão de RH (FERRAZ; RoCHA, 2011).

Ao analisarem como a estrutura organizacional da área de $\mathrm{RH}$ e seus agentes impactam sobre a gestão e sobre o alcance dos objetivos desse subsistema em uma instituição pública federal, Moura, Dias e Silva Júnior (2013) constataram a existência de traços burocráticos rígidos na estrutura da área, com a presença de componentes patriarcais na gestão aplicada e de agentes "sufocados" pelo trabalho, com pouco espaço para reflexão sobre a sua ação e sobre o que significa uma gestão estratégica de recursos humanos. Os autores mostraram que a configuração organizacional-administrativa dessa unidade comprometia a transição da gestão de $\mathrm{RH}$ de operacional e reativa para uma gestão mais estratégica e proativa.

A ausência de um conjunto sistematizado e coerente de diretrizes gerais no setor público federal brasileiro, que oriente as políticas de recursos humanos nas instituições, também parece contribuir para uma ação mais operacional e reativa das áreas de RH, dificultando uma atuação estratégica (MOURA; SOUZA, 2014).

Verifica-se, portanto, como bem destaca Carvalho et al. (2009), o reconhecimento da importância da gestão de RH na administração pública, embora a sua inserção estratégica nas estruturas e nos processos decisórios ainda seja algo a ser concretizado. O cenário descrito nesta seção justifica, assim, a escolha do setor público como um lócus interessante para pesquisar o fenômeno da contradição entre o discurso e a prática de $\mathrm{RH}$. 
Sobre essa questão, Khilji e Wang (2006) defendem a necessidade de distinguir o que é intenção e o que de fato é implementado na gestão de recursos humanos, de forma que os estudos possam explicar a real situação dessa área nas organizações. Contudo, não basta apenas reconhecer o que está sendo adotado, mas entender por que isso ocorre, ou seja, reconhecer os processos que estão determinando as políticas e práticas de RH. Para tanto, este estudo se propôs a analisar esse fenômeno sob a perspectiva da abordagem institucional.

\section{A abordagem institucional e sua relevância para a análise da gestão de RH}

A Teoria Institucional tem se destacado nos estudos organizacionais pelo potencial analítico e visão holística, que aumentam a capacidade de explicação dos fenômenos organizacionais complexos (SCOTT, 2008; PAAUWE, 2004).

Nesse sentido, a perspectiva institucional oferece uma possibilidade de análise mais dinâmica sobre o papel da gestão de pessoas em um contexto de mudança, revelando insights sobre os processos subjacentes que moldam essa gestão e os fatores contextuais que estão por trás das suas decisões. Assim, estudiosos têm analisado a gestão de $\mathrm{RH}$ sob uma perspectiva contextual, investigando como os arranjos institucionais atuam sobre a definição e implementação das políticas e práticas de RH. (Boon et al., 2009; LeE, 2011; LAcombe; Chu, 2008; Oliveira; PÁduA, 2012; PAAuWe, 2004).

Estudos mostram que na área de $\mathrm{RH}$ os mecanismos institucionais coercitivos, miméticos e normativos (DIMAGgIO; POWELL, 1983) atuam nos processos decisórios e influenciam e limitam a elaboração e implementação de políticas e práticas de gestão de pessoas.

Nessa área, os fatores institucionais se manifestam principalmente: (1) pela influência da legislação, em especial a trabalhista. No caso específico desta pesquisa, além de ser uma característica da área de RH ter sua ação alicerçada e orientada por leis e normas, o fato de tratar-se de um estudo no setor público (no qual a ação do agente público está pautada pela legalidade), sugere uma presença forte de mecanismos coercitivos; (2) sob a forma de imitação de estratégias de sucesso adotadas por outras organizações e adoção de tendências e de melhores práticas (mecanismos miméticos). Há uma atenção dirigida por parte das organizações aos modelos e práticas que se destacam no mercado e uma tentativa de copiálos, de forma que essas organizações pareçam modernas e profissionais (mesmo que tais práticas não se mostrem eficazes); e (3) pelo repertório dos funcionários, refletindo na disseminação e homogeneização de políticas e práticas de gestão de RH (mecanismos normativos). É inegável a influência decorrente da formação acadêmica, experiências anteriores de trabalho, participação em cursos, leitura de revistas de negócios, participação em associações, assim como da concorrência a certificações 
e prêmios. Observa-se uma linguagem comum, a troca de ideias e novidades e o compartilhamento de conhecimentos/instrumentos entre os profissionais.

A herança histórico-cultural das organizações constitui outro fator institucional relevante (LACOMBE; CHU, 2008; OLIVEIRA; PÁdUA, 2012). O setor público apresenta fortes componentes culturais que podem influenciar os processos decisórios, e influenciar a atitude e o comportamento dos servidores frente à implementação de processos de mudança. Há na administração pública de uma forma geral uma cultura voltada para o conservadorismo, conformismo, centralização, favorecimento político, descontinuidade e descompasso entre o discurso e a ação, que não só contribui para a ineficácia da ação do Estado, mas também para a desmotivação e descrença dos servidores, dificultando as inovações e mudanças. Intervir numa organização pública sem conhecer sua cultura pode levar a resultados inesperados e imprevisíveis, fazendo com que os servidores finjam que estão respeitando e trabalhando de acordo com as novas normas, quando na realidade querem restabelecer sua identidade. Componentes da formação histórico-cultural desse setor contribuem para o surgimento de fenômenos disfuncionais, tais como a valorização acentuada do tempo de serviço e a proteção dos cargos e funções, que reforçam comportamentos que operam na contramão de uma gestão voltada para resultados e baseada em competências (SCHIKMANN, 2010).

A perspectiva institucional pode ajudar, portanto, a entender como o discurso nessa área influencia a forma de difusão, incorporação e institucionalização dos novos conceitos e modelos de gestão de RH (DAMBRIN; LAMBERT; SPONEM, 2007; PHILLIPS; LAWRENCE; HARDY, 2004). Algumas possibilidades sobre o paradoxo discurso versus prática podem ser evidenciadas: por trás da implantação do modelo de RH estratégico estaria a intenção apenas de se criar uma "fachada", a fim de aparentar uma modernidade ou de passar credibilidade no meio? Tal cenário se configura dessa maneira porque a área de RH ainda está em transição ou ocorre em função da adoção indiscriminada de discursos, modelos e práticas, sem significado real para a organização? A existência (ou resistência) de práticas que se reportam ao modelo tradicional de gestão de RH pode indicar que se tratam de modelos legitimados na organização, sejam esses eficazes ou não? O caráter institucional dessas práticas pode, assim, explicar a continuação da sua utilização, independente da sua eficácia.

\section{Método}

A pesquisa realizada utilizou métodos quantitativos. Foi aplicado um survey, método de pesquisa social empírica que estuda uma amostra de uma determinada população para descrever, explicar e investigar essa população. Optou-se pelo método de survey interseccional, quando os resultados da pesquisa descrevem o fenômeno considerando a época do estudo (BABBIE, 1999). 
O universo da pesquisa abrange as unidades de RH dos órgãos federais que compõem a administração indireta no âmbito do Poder Executivo e que integram o Sistema de Pessoal Civil (Sipec) da administração pública federal, que totalizam 152 unidades de $\mathrm{RH}$ em todo território nacional, e seus respectivos dirigentes. Trabalhou-se com uma amostra probabilística e por adesão.

A opção por estudar o âmbito federal do setor público justifica-se por esse apresentar um sistema de gestão de RH mais bem estruturado (em comparação aos níveis estadual e municipal), assim como pelo fato de que, de modo geral, suas práticas de gestão servem como modelo inspirador para os governos estaduais e municipais brasileiros (OCDE, 2010). A escolha por instituições da administração indireta deve-se ao fato de que essas tendem a ter práticas de $\mathrm{RH}$ mais avançadas, em decorrência da maior autonomia e flexibilidade. Para se ter acesso ao universo da pesquisa, utilizouse o catálogo de endereço dos dirigentes de RH dos órgãos integrantes do Sipec, disponibilizado pelo Ministério do Planejamento (BRASIL, 2013).

Dentre os vários subsistemas de $\mathrm{RH}$, destacou-se nesta pesquisa o subsistema Desenvolvimento de Pessoal. Essa ênfase justifica-se pelo fato de a introdução da gestão por competências no setor público federal brasileiro ter se concentrado nas áreas de formação e de desenvolvimento dos servidores públicos (BRASIL, 2006); por essa área ser uma questão estratégica nas organizações e uma ferramenta de gestão de RH crucial no contexto de valorização do conhecimento e da capacidade de aprendizagem contínua como vantagens competitivas (AlbuQUerque, 2002; CARBONE et al., 2005; OCDE, 2010); e, finalmente, focar um subsistema específico (ao invés da gestão de RH em sua totalidade) permitiu uma análise mais aprofundada.

Neste estudo, foram considerados válidos ou com 'significado estatístico' os achados (inferências) em que $p \leq 0.05$, entendendo ' $p$ ' como a probabilidade de um determinado achado estatístico ter ocorrido por acaso. Para efeitos de análise dos dados, foram elaborados diversos indicadores matemáticos (indicadores de prática, discurso, forças isomórficas, resultados e hype $e^{1}$ ) a partir das variáveis do questionário aplicado. O uso desse recurso tem o propósito de buscar resultados significativos e uma descrição adequada do fenômeno. Com o propósito de avaliar o grau de confiabilidade e consistência interna desses indicadores, foi calculado o coeficiente alfa $(\alpha)$ de Cronbach, um dos procedimentos estatísticos mais usados para a mensuração da confiabilidade e consistência interna entre os itens de um questionário (COOPER; SCHINDLER, 2003).

Na pesquisa, são indicadores de práticas a existência de política interna de gestão de $\mathrm{RH}$, as atividades de $\mathrm{RH}$ praticadas, a atenção dispensada às atividades de RH nos

\footnotetext{
${ }^{1} \mathrm{O}$ termo Hype deriva de hyperbole (hipérbole) e é um conceito usado para indicar uma estratégia para enfatizar alguma coisa ou uma excessiva publicidade em torno de uma ideia. Neste estudo, é usado para expressar a discrepância entre o discurso e a prática na gestão de recursos humanos.
} 
últimos seis anos², as ações de adesão ao modelo de gestão por competências, o grau de implementação dos processos do modelo, o grau de adesão à Política Nacional de Desenvolvimento de Pessoal, as ações da PNDP praticadas, as ações de capacitação realizadas em 2012 e o orçamento realizado em 2012 com essas ações. Os indicadores de discurso envolvem a relevância atribuída pelos gestores de RH às atividades de $\mathrm{RH}$ e às ações de capacitação. O indicador de resultados envolve os impactos da implantação da gestão por competências. Os indicadores das forças isomórficas integram as variáveis relativas aos mecanismos isomórficos coercitivos, miméticos e normativos.

Como limitação do estudo, destaca-se o fato de ter analisado apenas a perspectiva do gestor, em vez de realizar uma pesquisa que envolvesse respondentes de múltiplos níveis, o que abre espaço para estudos futuros na área como indicado nas considerações finais deste artigo.

\section{Resultados e análise}

\section{Perfil da amostra}

Integraram a amostra 43 instituições públicas federais da administração indireta, ( $28 \%$ do universo da pesquisa). O quadro de pessoal nesses órgãos é de 2.759 servidores ( $D P=6.233,9$, Min.=19, Máx.=39.132). Participaram Autarquias (42\%), Fundações Públicas (37\%) e Autarquias Especiais (21\%), vinculadas às seguintes áreas: Educação (58\%), Cultura (9\%), Integração Social (7\%), Ciência, Tecnologia (5\%), Planejamento (5\%), Saúde (5\%), Desenvolvimento Agrário (2\%), Meio Ambiente (2\%), Previdência Social (2\%), Trabalho (2\%) e Transportes (2\%). A amostra envolveu instituições do Centro-Oeste (37\%), Nordeste (23\%), Sudeste (21\%), Sul (12\%) e Norte (7\%).

Dos gestores de recursos humanos, $56 \%$ são mulheres e $44 \%$ são homens, com idade média de 48 anos ( $D P=12$, Min.= 27, Máx.=69). Todos têm curso superior, sendo que $86 \%$ dos gestores são pós-graduados. O tempo médio no serviço público federal desses respondentes é de 21 anos ( $D P=12,6$, Min.=1, Máx.=40). O tempo médio na instituição pesquisada é de 13 anos ( $D P=11,9)$, variando de menos de um ano a 40 anos. O tempo médio de atuação na área de RH é de 11 anos ( $D P=9,42)$, variando de menos de um ano a 30 anos. A experiência (média) como gestor de RH na instituição pesquisada é de 5 anos ( $D P=5,9)$, variando de menos de um ano a 26 anos na função.

\footnotetext{
2 Esse intervalo de tempo foi estabelecido considerando o ano de homologação do Decreto no 5.707/2006, que instituiu a Política Nacional de Desenvolvimento de Pessoal e oficializou a incorporação do conceito de gestão por competências como referencial para a gestão de pessoas do setor público federal brasileiro.
} 


\section{Gestão}

A maioria dos gestores (60\%) considera que a gestão de pessoas exercida nas suas instituições não pode ser classificada como gestão estratégica. Das instituições que participaram da pesquisa, apenas $2 \%$ adotaram a gestão por competências e $23 \%$ optaram pelo modelo, embora esse ainda não esteja totalmente implantado. Os demais órgãos (75\%) ainda não implantaram a gestão por competências.

\section{Relação entre as práticas, discurso, forças isomórficas e resultados}

Foi utilizada a técnica de escalonamento multidimensional (SSA) para analisar as inter-relações entre as variáveis que integram os indicadores de prática, de discurso, das forças isomórficas e de resultados (Gráfico 1).

Gráfico 1 - Escalograma 2D das variáveis que integram os indicadores de prática, discurso, forças isomórficas e resultados

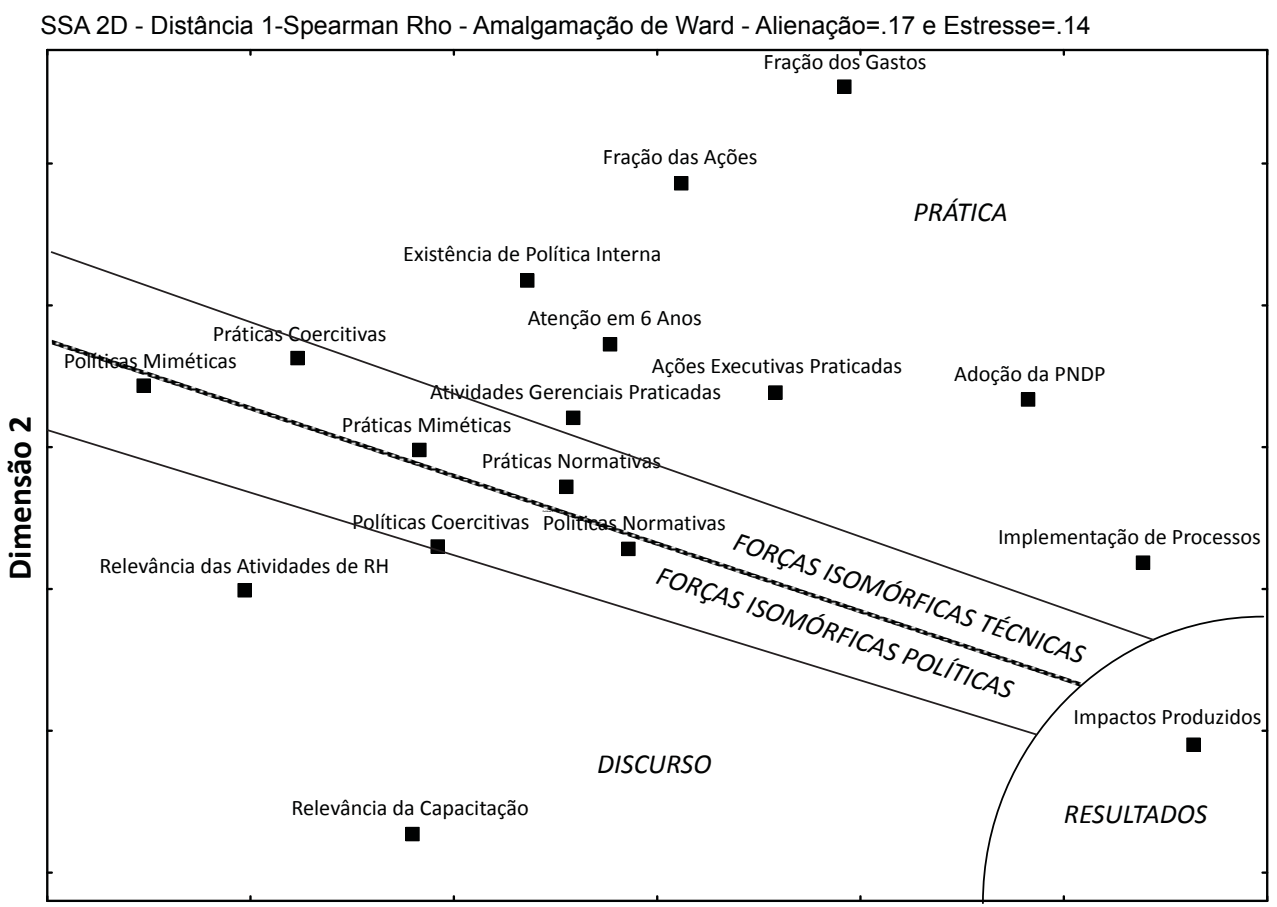

Dimensão 1

Fonte: Elaboração própria.

O escalograma foi divido em facetas com o objetivo de melhor compreender o fenômeno, à luz do arcabouço teórico estudado, e explicar a aglutinação natural e as distâncias entre as variáveis. No Gráfico 1, podem ser visualizadas quatro facetas, a prática, as forças isomórficas, o discurso e os resultados. 
A partir da análise dessas facetas, é possível concluir que:

a) as facetas referentes à prática (variáveis que integram o indicador de prática) e ao discurso (variáveis que compõem o indicador de discurso) encontram-se afastadas, confirmando a pouca relação entre o discurso e a prática na gestão de $\mathrm{RH}$;

b) as pressões isomórficas, embora estreitamente relacionadas entre si, são discerníveis quanto à ação da sua influência. Assim, subdividiu-se a faceta das influências isomórficas em: pressões isomórficas políticas e pressões isomórficas técnicas. Enquanto as primeiras se mostram mais relacionadas com o discurso, as forças isomórficas técnicas se mostram mais relacionadas com a prática; e

c) a faceta correspondente aos resultados, embora se apresente numa posição independente das demais variáveis, ainda mostra uma maior aproximação com as variáveis que integram o indicador de prática (e nenhuma relação com o discurso).

\section{A relação discurso e prática}

Foi realizado um estudo de regressão linear com o objetivo de verificar a relação entre o discurso e a prática na área de $\mathrm{RH}$ (Gráfico 2). 0 diagrama de dispersão mostra que quando a frequência do discurso é baixa, a diferença em relação à prática é pequena, mas essa diferença vai aumentando à medida que o discurso vai ficando mais intenso. Portanto, a discrepância é tanto maior quanto mais intenso é o discurso.

\section{Gráfico 2 - Diagrama de dispersão da relação discurso e prática}
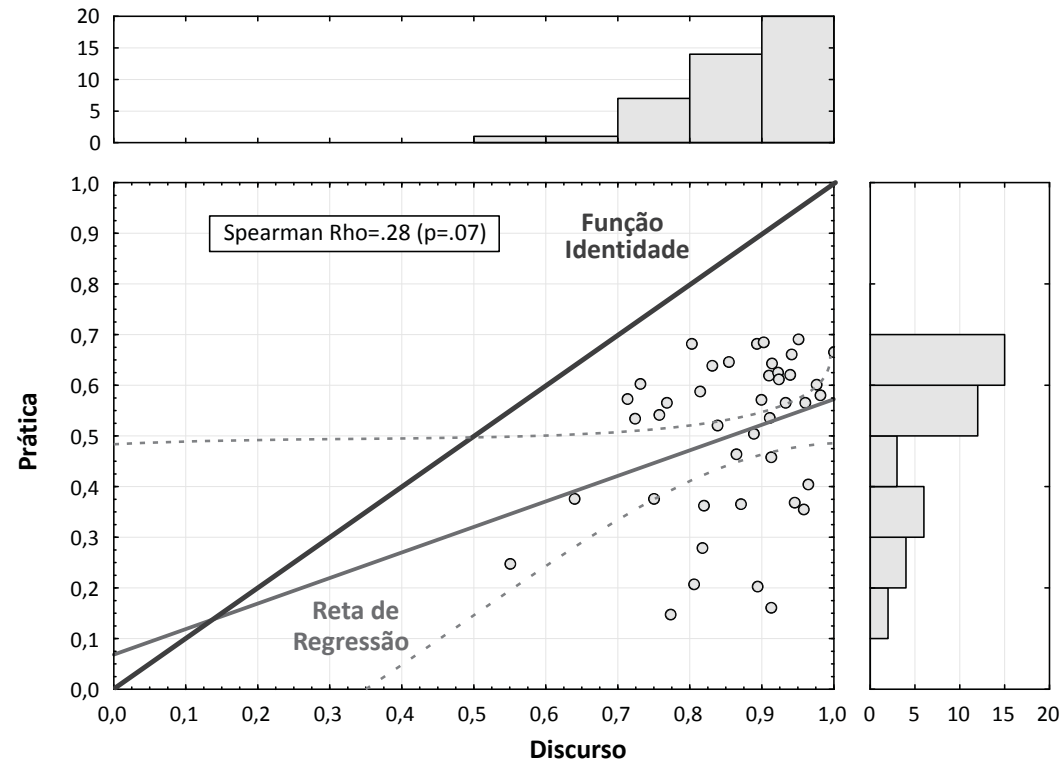

Fonte: Elaboração própria. 
Observe-se ainda que o gráfico de barras acima do diagrama de dispersão apresenta a distribuição do discurso, enquanto que o gráfico de barras à sua direita apresenta a distribuição da prática. No primeiro, os níveis mais altos do discurso são os mais frequentes, ou seja, o discurso é intenso. No segundo, a prática apresenta um limite, o que não ocorre com o discurso. O discurso, portanto, é mais efusivo que a prática.

\section{As forças isomórficas e suas relações}

O diagrama de dispersão apresentado no Gráfico 3 analisa a relação entre a influência das forças isomórficas políticas e a influência das forças isomórficas técnicas. A análise dessa relação mostra que essas forças são mais consistentes que dissonantes.

\section{Gráfico 3 - Diagrama de dispersão da relação entre as influências das forças isomórficas técnicas e políticas}
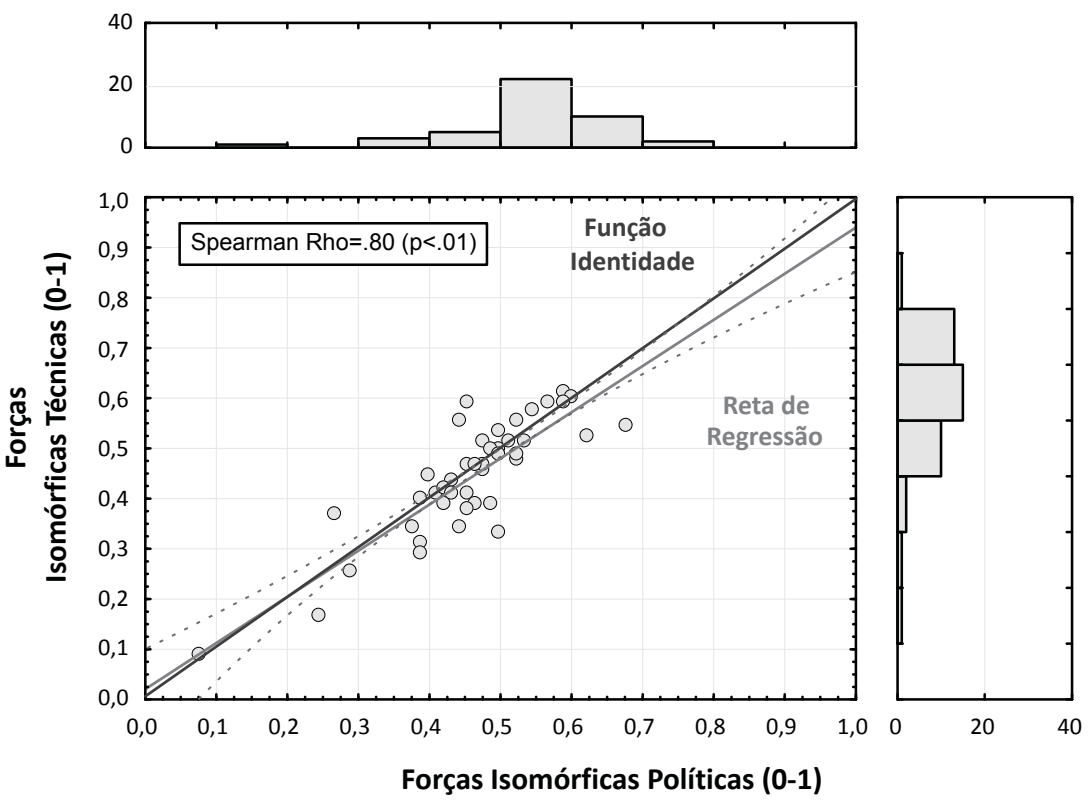

Fonte: Elaboração própria.

Com o objetivo de simplificar o estudo das correlações entre os indicadores de prática, discurso, forças isomórficas e resultados, optou-se por condensar (normalizar) as variáveis que integram os indicadores de prática, de discurso e das forças isomórficas (de modo a sempre produzir um valor numérico que varie entre zero e um). Assim, a análise da correlação entre os indicadores de pressões isomórficas, de prática e de discurso (Tabela 1) mostra correlação positiva e estatisticamente significativa entre eles. 
Tabela 1 - Correlações de Spearman dos indicadores de pressões isomórficas políticas e técnicas

\begin{tabular}{ccccc}
\hline Pressões isomórficas & \multicolumn{2}{c}{ Discurso } & \multicolumn{3}{c}{ Prática } \\
\cline { 2 - 5 } & Rho & $\mathrm{P}$ & Rho & $\mathrm{p}$ \\
\hline Políticas & 0.45 & $<.01$ & 0.51 & $<.01$ \\
Técnicas & 0.41 & 0.01 & 0.59 & $<.01$ \\
\hline
\end{tabular}

Fonte: Elaboração própria.

O diagrama apresentado no Gráfico 4 permite visualizar que, enquanto as pressões isomórficas apresentam graus de intensidade muito próximos, o discurso se destaca em relação à prática, apresentando uma intensidade bem maior, sendo essa diferença estatisticamente significativa.

Gráfico 4 - Intensidade das pressões isomórficas, discurso e prática

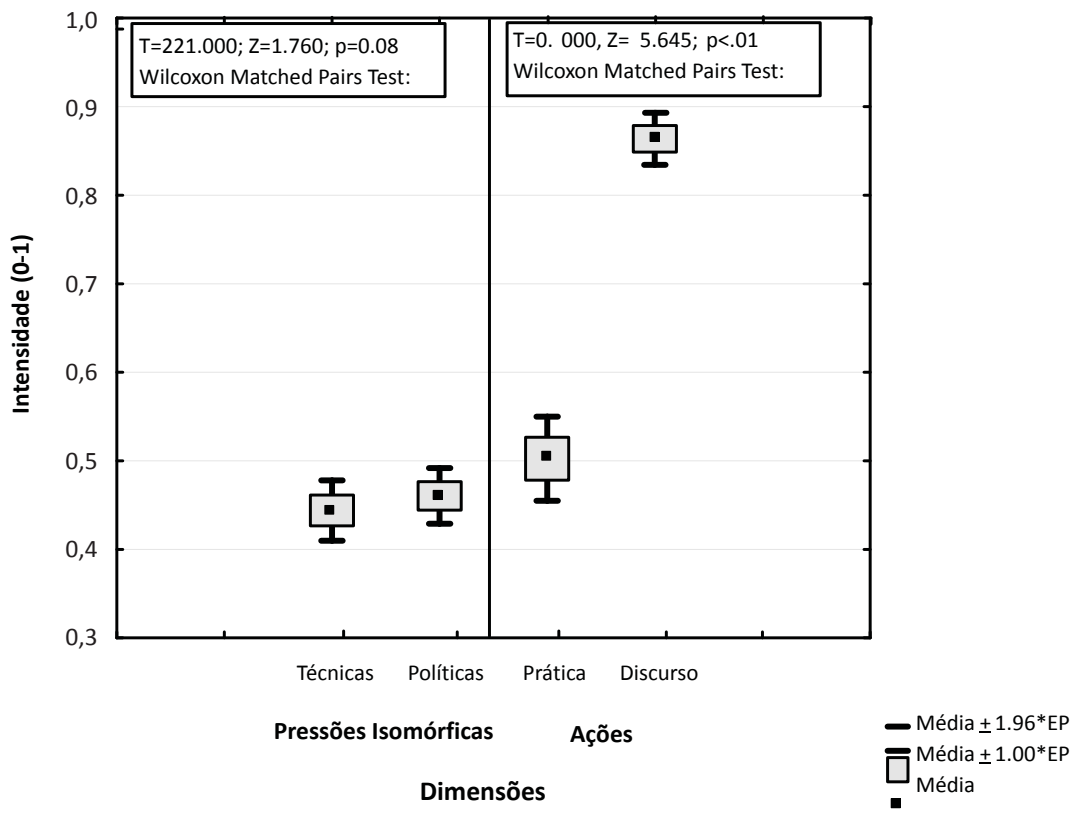

Fonte: Elaboração própria.

\section{A relação das pressões isomórficas, das práticas e do discurso com os resultados}

As pressões isomórficas e os indicadores de discurso não apresentaram relação significativa com o indicador de resultados; contudo, alguns indicadores de prática apresentaram relação com os resultados. Isso pode ser observado no Gráfico 1, a partir da análise da aproximação entre as variáveis que integram esses indicadores. 


\section{Condicionantes do Hype (discrepância entre o discurso e a prática)}

A experiência do gestor de RH no órgão apresentou uma correlação negativa, estatisticamente significativa, com o hype (Rho=-0.32, $\mathrm{r}^{2}=10 \%, \mathrm{t}(\mathrm{N}-2)=-2.166$, $\mathrm{p}=0.04)$. Logo, quanto maior a experiência do gestor na instituição, menor a discrepância entre o discurso e a prática.

Entre as variáveis que caracterizam a equipe de recursos humanos, a qualificação da equipe apresentou uma correlação negativa e estatisticamente significativa com o hype (Rho=-0.62, $\mathrm{r}^{2}=38 \%, \mathrm{t}(\mathrm{N}-2)=-4.872, \mathrm{p}=.01$ ). Assim, quanto mais qualificada a equipe de $\mathrm{RH}$, menor o hype. Esse apresentou, ainda, uma associação estatisticamente significativa com o fato de a instituição apresentar ou não uma gestão estratégica de pessoas. As instituições nas quais os gestores afirmaram não ter uma gestão estratégica de pessoas apresentaram um hype maior (Tabela 2).

Tabela 2 - 0 hype em função da gestão de RH

\begin{tabular}{lllllll}
\hline & \multicolumn{2}{l}{$\begin{array}{l}\text { Gestão estratégica } \\
(\mathrm{n}=16)\end{array}$} & \multicolumn{2}{l}{$\begin{array}{l}\text { Gestão não estraté- } \\
\text { gica }(\mathrm{n}=26)\end{array}$} & Mann-Whitney U \\
\cline { 2 - 7 } & Média & DP & Média & DP & z & $\mathrm{p}$ \\
\hline Hype & $54 \%$ & 0.29 & $127 \%$ & 1.22 & -2.215 & 0.03 \\
\hline
\end{tabular}

Fonte: Elaboração própria.

A discrepância entre o discurso e a prática (hype) não apresentou correlação estatisticamente significativa com as forças isomórficas de natureza política; contudo, apresentou correlação negativa e estatisticamente significativa com as forças isomórficas técnicas (Rho=-0.38, $r^{2}=14 \%, t(N-2)=-2.595, p=0.01$ ). Assim, quanto maior a influência das forças isomórficas técnicas, menor o hype.

\section{Análise da relação discurso e prática}

O escalograma multidimensional (Gráfico 1) mostra que o discurso e a prática na gestão de pessoas no setor público federal têm pouca relação. A análise feita a partir do Gráfico 2, por sua vez, revelou que, quando a frequência do discurso é baixa, a discrepância em relação à prática é pequena, mas essa diferença vai aumentando à medida que o discurso vai ficando mais intenso. Assim, a discrepância existente entre o discurso e a prática é tão maior quanto mais intenso for o discurso.

Os histogramas apresentados junto com o Gráfico 2 mostram, ainda, que o discurso se apresenta de forma mais frequente nos seus níveis mais altos, ou seja, constata-se um entusiasmo elevado no discurso. Já a distribuição da prática 
apresenta um limite, sem que os níveis mais altos sejam alcançados, a exemplo do que ocorre no discurso. O discurso, portanto, é mais efusivo que a prática. Assim, discurso e prática não apenas apresentam falta de relacionamento entre eles (que é fraco, na maior das hipóteses), mas também apresentam intensidades diferentes (Gráfico 4).

Alguns autores destacam o papel central do discurso no processo de institucionalização de novas práticas, enfatizando a sua importância para a internalização das novas lógicas por parte dos atores, a compreensão do seu papel e o seu posicionamento diante delas (DAMBrin; LAMBert; SPONEM, 2007; PHILLIPS; LAWRENCE; HARDY, 2004). Contudo, observa-se neste estudo que a incongruência entre o discurso na gestão de pessoas variou entre o mínimo de $18 \%$ e o máximo de $465 \%$ sobre a prática. A discrepância média entre o discurso e a prática foi de $99 \%$ (DP=103,35\%). Assim, não apenas se constata a discrepância entre o discurso e a prática de $\mathrm{RH}$, mas se observa que o grau dessa discrepância chega a níveis muito elevados.

Registre-se ainda que não houve, na amostra estudada, caso em que a prática tenha superado o discurso. Em todos os casos observados, o discurso é sempre mais efusivo que a prática. Isso justificou, inclusive, a adoção nesta pesquisa do termo hype para expressar o exagero no discurso.

A confirmação da discrepância entre o discurso e a prática neste estudo é evidenciada, portanto, pelo afastamento dessas variáveis no Gráfico 1, pela pouca relação (Gráfico 2) e pela diferença da intensidade que apresentam (Gráfico 4).

\section{Análise das forças isomórficas e suas relações}

A importância relativa dos mecanismos institucionais isomórficos depende da situação investigada e do seu contexto institucional. As forças isomórficas variam em termos de força, conteúdo, motivação e ação dependendo do contexto, do segmento de atividade da organização e de suas características internas (Boon et al., 2009).

Observando-se o Gráfico 1, fica evidente que as pressões isomórficas de natureza política ligam-se mais ao discurso e as pressões isomórficas técnicas estão mais associadas aos indicadores de prática, sugerindo que as forças isomórficas atuam de forma distinta sobre o discurso e sobre a prática. Contudo, o diagrama de dispersão que analisa a relação entre a influência das pressões isomórficas técnicas e a influência das pressões isomórficas políticas (ver Gráfico 3) mostra que o discurso e a prática não se contradizem em nível de pressões isomórficas. As pressões isomórficas técnicas e políticas são estreitamente relacionadas (Rho=.80, 
p<.01) e são muito próximas em termos de intensidade e dinâmica (Gráfico 4). Essas forças são mais consistentes que dissonantes; contudo, seus impactos são distintos.

Ao se analisar a correlação entre os indicadores das forças isomórficas sobre o discurso e sobre a prática de $\mathrm{RH}$ (Tabela 1), observa-se uma correlação positiva e estatisticamente significativa entre eles. Embora a intensidade das forças isomórficas técnicas com a prática seja maior do que a intensidade das forças isomórficas políticas com o discurso, não é possível afirmar que a resposta das práticas à influência das forças isomórficas é mais intensa do que a resposta do discurso, considerando que o tamanho da amostra não permite estimar essa diferença com mais precisão.

Ao relacionar a influência das forças isomórficas com o discurso e com a prática, explica-se a sensibilidade das organizações a essas forças, ou seja, a reatividade institucional (Figura 1). A intensidade da resposta às forças isomórficas, tanto no que diz respeito à dimensão da prática, como à dimensão do discurso, é praticamente a mesma (registre-se que a diferença entre as respostas não é estatisticamente significativa: $p=.39$ no teste da diferença entre correlações).

Figura 1 - Reatividade institucional às forças isomórficas políticas e técnicas

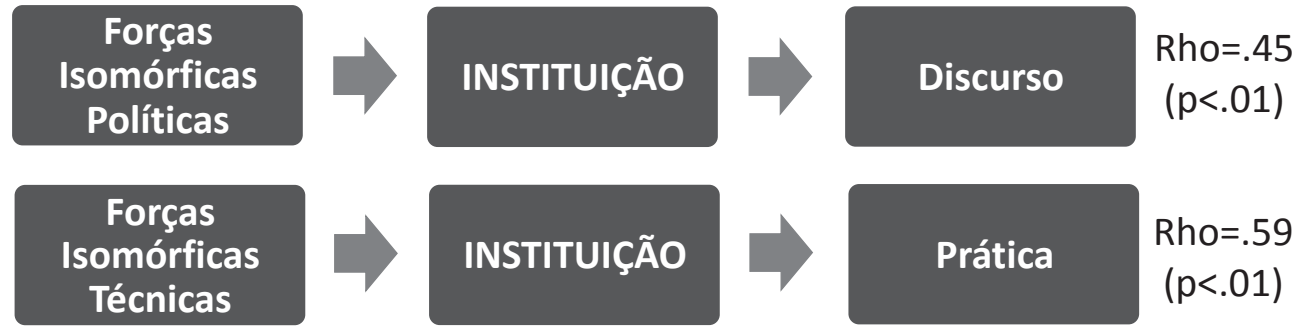

Fonte: Elaboração própria.

Portanto, embora as pressões isomórficas políticas e técnicas sejam mais consistentes que dissonantes e atuem com a mesma intensidade (Gráfico 4) e a prática e o discurso respondam a essas pressões com a mesma intensidade (Tabela 1 e Figura 1), o que se observa no Gráfico 3 é que o discurso se apresenta nos níveis mais altos, enquanto que a prática apresenta níveis ainda a serem alcançados. Logo, mesmo que a prática reaja com a mesma intensidade que o discurso, é o discurso que se sobressai.

Assim, os resultados sugerem que a discrepância entre o discurso e a prática não se trata apenas de um efeito institucional, essa discrepância é pré-existente. Está se falando de um estado de coisas que vêm de uma origem anterior à situação atual. A prática estaria respondendo às influências das forças isomórficas, assim como o discurso; contudo, mantém-se a discrepância já existente (condições iniciais). Essa constatação pode estar chamando a atenção para uma característica 
da natureza dessa relação: o discurso representa ou está relacionado a um "ideal" a ser alcançado (DAMBRIN; LAMBERT; SPONEM, 2007). Contudo, mesmo expressando um "ideal", lembre-se que quanto mais efusivo o discurso, maior a discrepância (Gráfico 2), e que a discrepância neste estudo atingiu níveis elevados. Enquanto a distribuição do discurso apresentada no Gráfico 2 está saturada nos valores altos, a prática está saturada nos valores mais baixos, ou seja, a prática apresenta-se deficitária.

Portanto, embora as pressões institucionais atuem de forma diferente sobre o discurso e a prática, não é isso que está contribuindo para a discrepância entre o discurso e a prática na gestão de pessoas no setor público federal brasileiro. Essa incongruência não reflete um efeito institucional. Constata-se que aspectos relacionados à dinâmica interna das organizações, como a ausência de uma gestão estratégica e a equipe de RH pouco qualificada, estão impactando a capacidade dessas instituições de responderem às pressões institucionais, contribuindo para a discrepância entre o discurso e a prática. Ainda com relação a essa dinâmica, verificou-se que a experiência do gestor na instituição, muito provavelmente pela importância do conhecimento da herança histórico-cultural da instituição nos processos de mudança, tem um papel relevante. Embora discurso e prática respondam às forças isomórficas com praticamente a mesma intensidade, o discurso apresenta-se efusivo e a prática apresenta-se deficitária. Portanto, condições préexistentes estariam contribuindo para essa discrepância na gestão de RH no setor público federal brasileiro (Figura 2).

\section{Figura 2 - Mapa conceitual da discrepância entre o discurso e a prática de RH no setor público}

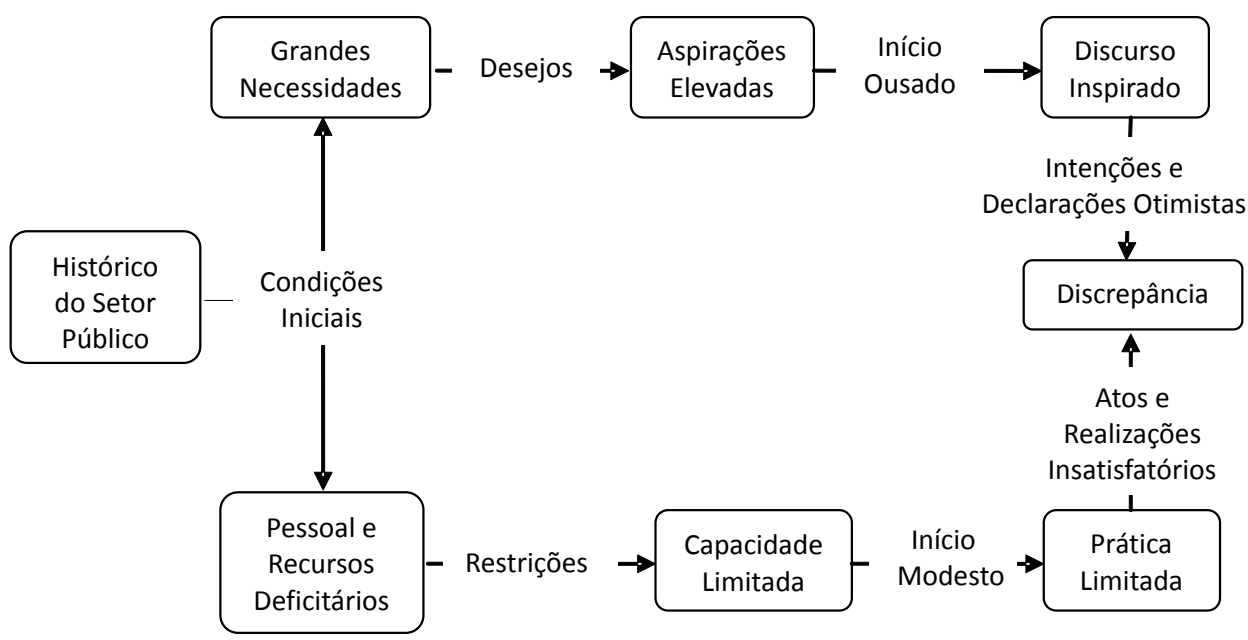

Fonte: Elaboração própria. 
De um lado estão demandas plurais e complexas que exigem ações eficazes e resultados de qualidade que inspiram um início ousado, no que se refere ao discurso. Do outro lado, restrições internas e aspectos históricos das instituições estariam comprometendo a sua capacidade de resposta, contribuindo para uma resposta modesta. Está se falando de um discurso efusivo, atrelado a ideais elevados, e de uma prática limitada, em função de um legado histórico-cultural e da ausência de uma base estrutural que favoreça a implementação, de fato, do modelo de gestão por competências.

\section{Considerações finais}

O estudo analisou a discrepância entre o discurso e a prática da gestão de $\mathrm{RH}$ em 43 instituições do setor público federal brasileiro. Os resultados indicam que a inserção estratégica da área de $\mathrm{RH}$ nas estruturas e nos processos decisórios das instituições públicas ainda é uma questão a ser conquistada. Contudo, apesar da baixa incidência de instituições com gestão estratégica de $\mathrm{RH}$, as evidências ratificam a importância de uma atuação estratégica. As instituições cujos gestores afirmaram adotar uma gestão estratégica apresentaram uma associação negativa, estatisticamente significativa, com a discrepância entre o discurso e a prática. Portanto, ao criar condições para uma atuação mais eficiente e eficaz da área de RH, a gestão estratégica parece contribuir para diminuir a discrepância entre o discurso e a prática.

A qualificação do profissional de RH apresentou correlação negativa com a discrepância entre o discurso e a prática. Destaca-se, assim, a importância de que os profissionais de recursos humanos adquiram novos aprendizados, baseados nos novos referenciais exigidos para a gestão de pessoas, sendo essa uma das condições para que a área de recursos humanos efetivamente atue de forma mais eficiente e eficaz e que responda aos desafios impostos com a sua integração à estratégica organizacional.

Os resultados sugerem que a experiência do gestor de $\mathrm{RH}$ na instituição e, consequentemente, o conhecimento da dinâmica histórico-cultural da instituição constitui fator relevante para a minimização da discrepância entre o discurso e a prática na área de $\mathrm{RH}$. Os achados corroboram o caráter histórico-contextual da área de gestão de pessoas e a importância do conhecimento das peculiaridades da administração pública nas intervenções em instituições desse setor.

Sobre a discrepância entre o discurso e a prática, os resultados desta pesquisa corroboram as evidências empíricas citadas na seção introdutória deste trabalho, de que há uma incongruência entre o discurso e a prática da gestão de $\mathrm{RH}$. $\mathrm{O}$ discurso exerce um papel central na institucionalização de novas práticas e valores, 
ao fornecer argumentos de que essas inovações são racionais e eficientes, e na mobilização da instituição em direção às mudanças pretendidas. Contudo, neste estudo a discrepância entre o discurso e a prática chegou a níveis muito elevados, o que motivou o uso do termo "hype" para expressar a efusão excessiva do discurso.

Ao analisar a relação discurso e prática no contexto da gestão de pessoas no setor público federal brasileiro, à luz da perspectiva institucional, observou-se que as forças isomórficas, embora apresentem uma relação estreita entre si, são discerníveis quanto à sua ação sobre as políticas e à sua ação sobre as práticas de recursos humanos, sendo que a primeira apresenta uma correlação mais forte com o discurso (natureza política), enquanto a segunda apresenta uma correlação mais forte com as práticas de RH (natureza técnica). Contudo, não é isso que está contribuindo para a discrepância entre o discurso e a prática na gestão de RH. Condições iniciais estariam contribuindo para um discurso efusivo e uma prática deficitária. Os resultados sugerem que as instituições apresentam restrições relacionadas ao seu quadro de pessoal e à sua dinâmica interna que limitam a capacidade organizacional, refletindo em práticas insatisfatórias. Questões internas, como a ausência de uma gestão estratégica e uma equipe de RH pouco qualificada, assim como a herança histórico-cultural das organizações e as peculiaridades do setor público, impactam as práticas, os resultados e a discrepância entre o discurso e a prática da gestão de pessoas no setor público federal.

Implementar novos modelos de gestão de pessoas, a exemplo da gestão por competências, sem considerar que essas condições existem e que devem ser tratadas, só vai contribuir para a permanência de práticas tradicionais e ineficazes e impedir que, de fato, se aplique uma gestão estratégica de pessoas no setor público federal.

Novos estudos podem contribuir para a construção de um conjunto de conhecimentos característicos da gestão pública de recursos humanos e suscitar outros insights sobre o hiato entre o discurso e a prática nessa área. Assim, para estudos futuros, recomenda-se ampliar a amostra pesquisada, inclusive expandindo o universo estudado e envolvendo órgãos de natureza jurídica diferente (empresas públicas e sociedades de economia mista), órgãos da administração direta e até mesmo de outros poderes. É interessante, também, considerar perspectivas de respondentes de múltiplos níveis, investigando a influência desses atores nas políticas e práticas da área de $\mathrm{RH}$. 


\section{Referências bibliográficas}

AgUIAR, J. E.; MELLO JÚNIOR, E. Mudanças e paradoxo organizacional: contradições entre o discurso e a prática. In: EnANPAD, 30, Salvador, 2006. Anais... Salvador: ANPAD, 2006.

ÄHLSTRÖM, J. Corporate response to CSO criticism: decoupling the corporate responsibility discourse from business practice. Corporate Social Responsibility and Environmental Management, v. 17, n. 2, p. 70-80, mar./apri. 2010.

Albuquerque, L. G. A gestão estratégica de pessoas. In: Fleury, M. T. L. (Org.). As pessoas na organização. São Paulo: Editora Gente, 2002. p. 35-50.

AMARAl Filho, R. G.; MACHADO-DA-Silva, C. L. Estratégia e teoria institucional: uma proposta discursiva de integração. In: EnAnpad, 30, Salvador, 2006. Anais... Salvador: Anpad, 2006.

AMARAL, H. K. Desenvolvimento de competências de servidores na administração pública brasileira. RSP, Brasília, v. 57, n, 4, p. 549-563, out./dez., 2006.

Ashton, C.; HAfFEnden, M.; LAMBERT, A. The "fit for purpose" HR function. Corporate Research Forum. Strategic HR Review, v. 4, n. 1, nov./dec. 2004.

BABBIE, E. Métodos de pesquisas de survey. Belo Horizonte: Ed. UFMG, 1999.

BARBOSA, A. C. Q. Relações de trabalho e recursos humanos em busca de identidade. $R A E$, v. 45, p. 121-126, 2005.

BarbosA, A. C. Q.; Ferraz, D. M.; LoPES, D. P. T. Competências nas organizações: o discurso e a prática na gestão de pessoas. In: EnANPAD, 26, Anais... Salvador: ANPAD, 2002.

Boon, C. et al. Institutional pressures and HRM: developing institutional fit. Personnel Review, v. 38, n. 5, p. 492-508, 2009.

Boselie, P.; BREWSTER, C.; PAAUWE, J. In search of balance - managing the dualities of HRM: an overview of the issues. Personnel Review, v. 38, n. 5, p. 461-471, 2009.

BRASIL. Decreto no 5.707, de 23 de fevereiro de 2006. Institui a Política e as Diretrizes para o Desenvolvimento de Pessoal da administração pública federal direta, autárquica e fundacional, e regulamenta dispositivos da Lei no 8.112, de 11 de dezembro de 1990. Diário Oficial da República Federativa do Brasil, Brasília, DF, 24 de fevereiro de 2006.

Ministério do Planejamento, Orçamento e Gestão. Secretaria de Recursos Humanos. Relatório final da conferência nacional de recursos humanos da administração pública federal 2009. Brasília, MP, 2009.

Ministério do Planejamento, Orçamento e Gestão. Catálogo de endereço dos dirigentes de recursos humanos dos órgãos integrantes do SIPEC. 2013. BURKE, R. J.; COOPER, C. L. The new world of work and organizations: implications for human resource management. Human Resource Management Review, v. 16, n. 2, p. 83-85, jun. 2006.

CABrera, E. F.; CARRetero, J. M. Human Resource Management in Spain: are cultural barriers preventing the adoption of global practices? Management Research, v. 3, n. 2, p. 149-160, 2005. 
CARbone, P. P. et al. Gestão por competências e gestão do conhecimento. Rio de Janeiro: Editora FGV, 2005. (Série Gestão de Pessoas).

CARVAlHo, A. I. et al. Escolas de governo e gestão por competências: mesa-redonda de pesquisa-ação. Brasília: ENAP, 2009.

CAStRo, J. H. M.; KILIMNIK, Z. M.; SANT'ANNA, A. S. Modernidade organizacional em gestão de pessoas como base para a incorporação de modelo de gestão por competências. RAC-Eletrônica, v. 2, n. 1, p. 105-122, jan./abr. 2008.

CESAR, A. M. R.V. C.; BIDO, D. S.; SAAD, S. M. A "evolução" da área de recursos humanos, em termos de importância estratégica e capacidade instalada: cinco anos de levantamento em empresas que atuam no Brasil. In: EnANPAD, 31, Anais... Rio de Janeiro: ANPAD, 2007.

CODA, R. et al. Strategic HR? A study of the perceived role of HRM departments in Brazil and Peru. Brazilian Administration Review, Curitiba, v. 6, n.1, p. 15-33, 2009.

COOPER, D. R.; SCHINDLER, P. S. Métodos de pesquisa em administração. 7 ed. Porto Alegre: Bookman, 2003.

DAMBrin, C.; LAMBERT, C.; SPONEM, S. Control and change: analysing the process of institutionalisation. Management Accounting Research, v. 18, n. 2, 2007.

DEMO, G. et al. Políticas de gestão de pessoas no novo milênio: cenário dos estudos publicados nos periódicos da área de administração entre 2000 e 2010. Revista de Administração Mackenzie, v. 12, n. 5, set./out. 2011.

DIAS, C. G.; LOPES, F. T.; DALLA, W. D. Evolução dos Recursos Humanos nas empresas? Da retórica às práticas antigas com novas roupagens. EnANPAD, 31, Anais... Rio de Janeiro: ANPAD, 2007.

DIMAgGIO, P. J.; POWELL, W. W. The iron cage revisited: institutional isomorphism and collective rationality in organizational fields. American Sociological Review, v. 48, n. 2, p. 147-160, apr. de 1983.

DUTRA, J. S. Competências: conceitos e instrumentos para a gestão de pessoas na empresa moderna. São Paulo: Atlas, 2008.

EISENHARDT, K. M. Paradox, spirals, ambivalence: the new language of change and pluralism. The Academy of Management Review, v. 25, n. 4, p. 703-705, 2000.

Ferraz, V. N.; RochA, C. R. Políticas de recursos humanos no setor público: o que esperam os servidores de uma organização pública federal? In: EnGPR, 3, Anais... João Pessoa: ANPAD, 2011.

FIgUEIREDO, M. D. et al. Atuação estratégica de RH: uma proposta de categorização. In: EnANPAD, 32, Anais... Rio de Janeiro: ANPAD, 2008.

FONSECA, D. R.; MENESES, P. P. M. Elementos de institucionalização da gestão estratégica de pessoas no setor público. EnGPR,4, Anais... João Pessoa: ANPAD, 2011.

Freitas, W. R. S.; Jabbour, C. J. C.; SAntos, F. C. A. Rumo à sustentabilidade organizacional: uma sistematização sobre o passado, o presente e o futuro da gestão de recursos humanos. In: EnGPR, 2, Curitiba, 2009. Anais... Curitiba: ANPAD, 2009.

GILL, C.; MEYER, D. The role and impact of HRM policy. International Journal of Organizational Analysis, v. 19, n. 1, p. 5-28, 2011. 
Guerreiro, R.; Frezatti, F.; CASAdo, T. Em busca de um melhor entendimento da contabilidade gerencial através da integração de conceitos da psicologia, cultura organizacional e teoria institucional. Rev. Contab. Finanç., São Paulo, v. 17, n. spe, ago. de 2006.

GUEST, D. E. Human resource management and performance: still searching for some answers. Human Resource Management Journal, v. 21, n. 1, p. 3-13, 2011.

KEPES, S.; DelerY, J. E. HRM systems and the problem of internal fit. In: Boxall, P.; PURCELL, J.; WRIGHT, P. The Oxford Handbook of Human Resource Management. Oxford: Oxford University Press, 2007. p. 385-404.

KHILJI, S. E.; WANG, X. 'Intended' and 'implemented' HRM: the missing linchpin in strategic human resource management research. The International Journal of Human Resource Management, v. 7, n. 17, p. 1171-1189, July 2006.

KOCHAN, T. A. Social legitimacy of the HRM profession: a US perspective. In: BoxALL, P.; PURCELL, J.; WRIGHT, P. The Oxford Handbook of Human Resource Management. Oxford: Oxford University Press, 2007. p. 599-619.

LACOMBE, B. M. B.; CHU, R. A. Políticas e práticas de gestão de pessoas: as abordagens estratégica e institucional. $R A E$, v. 48, n. 1, p. 25-35, jan./mar. 2008.

LACOMBE, B. M. B.; TONELLI, M. J. O discurso e a prática: o que nos dizem os especialistas e o que nos mostram as práticas das empresas sobre os modelos de gestão de recursos humanos. RAC, Curitiba v. 5, n. 2, maio/ago. 2001. p. 157-174.

O paradoxo básico da administração de recursos humanos: o discurso versus a prática de gestão de pessoas nas empresas. In: VASCONCELOS, F. C.; VASCONCElos, I. F. G. Paradoxos organizacionais: uma visão transformacional. São Paulo: Pioneira Thomson Learning, 2004. p. 53-74.

LE BOTERF, G. Avaliar a competência de um profissional: três dimensões a explorar. Reflexão RH, Lisboa, p. 60-63, jun. 2006

LEANA, C. R.; BARRY, B. Stability and change as simultaneous experiences in organizational life. The Academy of Management Review, v. 25, n. 4, p. 753-759. 2000.

LEE, A. Understanding Strategic Human Resource Management through the paradigm of Institutional Theory. International Employment Relations Review, v.17, n.1, 2011.

LEGGE, K. Human Resource Management: rhetorics and realities. Anniversay Edition. London: Palgrave Macmillan, 2005.

LEWIS, M. W. Exploring paradox: toward a more comprehensive guide. The Academy of Management Review, v. 25, n. 4, p. 760-776, 2000.

LIEBoWITZ, J. The role of HR in achieving a sustainability culture. Journal of Sustainable Development, v. 3, n. 4, December, 2010.

MourA, A. L. N.; DiAS, C. M.; Silva JúNIOR, A. S. Recursos Humanos sob a Luz do Modelo de Organização Multidimensional-Reflexivo: analisando a área de recursos humanos de uma instituição pública federal. In: EnANPAD, 37, Rio de Janeiro, 2013. Anais... Rio de Janeiro: ANPAD, 2013. 
MourA, A. L. N; SouzA, B. C. A Gestão Pública de Recursos Humanos: uma Análise em Instituições da Administração Indireta do Setor Público Federal à Luz da Abordagem Contemporânea da Gestão de Recursos Humanos. In: EnAPG, 6, Belo Horizonte. Anais... Belo Horizonte: ANPAD, 2014.

MARConI, N. A gestão de recursos humanos no governo federal: diagnóstico e proposta. Digesto Econômico, n. 457, p. 80-98, Abr. 2010.

NASCIMENTO, T. A.; SIMÕES, J. M. O sentido do trabalho no serviço público: reflexões a partir dos servidores da área de RH. In: EnGPR, 3, João Pessoa. Anais... João Pessoa: ANPAD, 2011.

OCDE. Organização para a cooperação e o desenvolvimento econômico. Avaliação da gestão de recursos humanos no governo - Relatório da OCDE: Brasil 2010 Governo Federal. OCDE. 2010.

OliveirA, L. M. B.; PÁDUA, M. M. Contextualized theory as a tool to identify the forces of shaping Human Resource Management: an exploratory study in wineries from the Northeast of Brazil. Business and Management Review, v. 2, n. 1, p. 39-49, 2012.

PAAUWE, J. HRM and performance: achieving long term viability. Oxford: Oxford University Press, 2004.

Phillips, N.; LAWRence; T. B.; HARDY, C. Discourse and institutions. Academy of Management Review, v. 29, n. 4, p. 635-652, 2004.

PIRES, A. K. et al. Gestão por competências em organizações de governo. Brasília: ENAP, 2005.

RAMLALL, S. J. Identifying and understanding HR competencies and their relationship to organizational practices. Applied HRM Research, v. 11, n. 1, p. 27-30, 2006.

RASMUSSEN, E.; ANDERSEN, T.; HAWORTH, N. Has the strategic role and professional status of human resource management peaked in New Zealand? Journal of Industrial Relations, v. 52, n. 1, p. 103-118, 2010.

RIMANOCZY; I.; PEARSON, T. Role of HR in the new world of sustainability. Industrial and Commercial Training, v. 42, n. 1, p 11-17, 2010.

SCHIKMANN, R. Gestão estratégica de pessoas: bases para a concepção do curso de especialização em gestão de pessoas no serviço público. In: CAMÕES, M. R.S.; PANtojA, M. J.; Bergue, S. T. (Org.). Gestão de pessoas: bases teóricas e experiências no setor público. Brasília: ENAP, 2010. P. 9-28.

ScotT, W. R. Approaching adulthood: the maturing of institutional theory. Theory and Society, v. 37, p. 427-442, 2008.

SILVA, J. R. G.; VergarA, S. C. Sentimentos, subjetividade e supostas resistências à mudança. $R A E$, v. 43, n. 3, p. 10-21, jul/set. 2003.

TANURE, B.; EVANS, P.; CANÇADO, V. L. As quatro faces de RH: analisando a performance da gestão de recursos humanos em empresas no Brasil. RAC, Curitiba, v. 14, n. 4, p. 594-614, jul./ago. 2010.

VAsconcelos, F. C.; VAsconcelos, I. F. G. Paradoxos organizacionais: uma visão transformacional. São Paulo: Pioneira Thomson Learning, 2004.

ZARIFIAN, P. O modelo da competência: trajetória histórica, desafios atuais e propostas. São Paulo: Editora Senac São Paulo, 2003. 
Ana Lúcia Neves de Moura

Possui doutorado em Administração pela Universidade Federal de Pernambuco (UFPE). É Analista em Ciência e Tecnologia na Fundação Joaquim Nabuco (Fundaj). Contato: ana.moura@fundaj.gov.br

Bruno Campello de Souza

Possui doutorado em Psicologia Cognitiva pela Universidade Federal de Pernambuco (UFPE). É Professor Adjunto da Universidade Federal de Pernambuco (UFPE). Contato: bcampello@uol.com.br 